\title{
El concepto de belleza en el mundo antiguo y su recepción en Occidente
}

\author{
David KONSTAN \\ New York University \\ david_konstan@brown.edu
}

RESUMEN: El concepto occidental de belleza debe mucho, por supuesto, a las ideas y los ejemplos de la antigua Grecia. Desde el Renacimiento, las obras de arte y la poesía griegas y romanas han sido arquetipos de la perfección estética. Sin embargo, ¿coincidía completamente la idea griega de belleza con la nuestra? ¿Veían belleza donde la vemos nosotros? En este trabajo argumento que hay diferencias importantes entre la idea clásica de belleza y su concepción moderna, y que la tradición es menos continua y coherente de lo que se supone comúnmente.

\section{The Concept of Beauty in the Ancient World and its Reception in the West}

\begin{abstract}
The western concept of beauty owes much, needless to say, to the ideas and example of ancient Greece. Ever since the Renaissance, Greek and Roman art and poetry have been viewed as archetypes of aesthetic perfection. But did the Greek idea of beauty coincide entirely with our own? Did they perceive beauty where we do? In this paper, I argue that there are significant differences between the classical and the modern ideas of beauty, and that the tradition is less continuous and consistent than is commonly supposed.
\end{abstract}

PALABRAS ClaVE: Belleza, arte, estética, $x \alpha ́ \lambda \lambda$ os.

KEYwORDS: Beauty, art, aesthetics, xá $\lambda \lambda$ os.

FECHA DE RECEPCIÓN: 24 de enero de 2012.

FECHA DE ACEPTACIÓN: 12 de agosto de 2012. 



\title{
El concepto de belleza en el mundo antiguo y su recepción en Occidente ${ }^{1}$
}

\author{
David KONSTAN
}

Es un lugar común afirmar que el concepto actual de belleza debe mucho a los modelos de la Grecia clásica y que se formó básicamente durante el Renacimiento, cuando el pasado clásico empezó a recuperarse y el gusto se rebeló contra las estilizadas formas de la Edad Media. Sin embargo, hay una cuestión que pocas veces se plantea en relación con este tema, y es precisamente la que voy a tratar aquí: La idea de belleza que el Renacimiento - y los artistas, historiadores y teóricos del arte que siguieron tras él- extrajo de su encuentro con la pintura y escultura clásicas, ¿se corresponde realmente con lo que los propios griegos de la antigüedad identificaban como "bello"? Aún más, ¿tenían los antiguos griegos y romanos una noción clara de belleza, o más bien nosotros nos dedicamos a proyectar sobre ellos nuestro propio concepto, sin considerar sus valores o la posibilidad de que la noción misma de lo estético sea - como lo es también la palabra - una creación moderna?

Llevo ya muchos años dedicándome al estudio de la historia de los términos en que se expresan en griego y en latín valores básicos y emociones, y he investigado si cosas tan familiares como la amistad, la cólera o el perdón se entendían en la antigüedad más o menos como lo hacemos nosotros o si hay diferencias importantes. Aquí voy a plantear una cuestión semejante acerca de las nociones antiguas y modernas de la belleza, aunque en este caso hay un matiz especial, pues la idea moderna de belleza se considera normalmente como inspirada directamente del ideal clásico. Pero este ideal, además, se recuperó sólo tras un pa-

${ }^{1}$ Este artículo fue presentado en el III Congreso Internacional de Estudios Clásicos en México. La tradición clásica en Occidente (29 de agosto al 2 de septiembre de 2011). Por esta razón, conserva el tono de la conferencia oral, con toques de humor (;espero!) e informalidad. Es cierto que no la he adaptado totalmente al estilo seco de las revistas "científicas", pero creo que se puede, de vez en cuando, permitirse alguna excepción, un poco más ligera y divertida (si de verdad lo es). Agradezco las observaciones de los dictaminadores. 
réntesis de siglos; por tanto, la noción de belleza está inextricablemente vinculada a la historia de la recepción, en general, de la cultura clásica. Pero ¿qué sucede si la belleza que los modernos percibían en las obras de arte clásicas, y que son la base sobre la que formaron sus ideales estéticos, era diferente de lo que los griegos y romanos mismos entendían por belleza? En ese caso, tendríamos un extraño y fascinante ejemplo en el que la revitalización consciente de un antiguo concepto era, de hecho, una distorsión y una falsa percepción, que no sólo influyó sobre la historia subsiguiente del arte moderno, sino que también condicionó - y puede ser que falsamente - nuestra visión del arte antiguo en sí.

Voy a argumentar que éste es, de hecho, el caso, y que lo que consideramos "bello" en el arte no se corresponde con el concepto griego de belleza. Pero para llegar a ese punto, tengo que decir algo sobre cómo entendemos actualmente la belleza en general, y en el arte en particular, y también - y ésta es la parte más difícil y la que nos llevará a conclusiones más novedosas - algo sobre cómo entendían la belleza los propios griegos. Pero antes de embarcarme en el análisis de estos términos, me gustaría llevar a cabo un pequeño experimento o encuesta. Aquí presento dos imágenes muy diferentes entre sí, una moderna, la otra clásica:

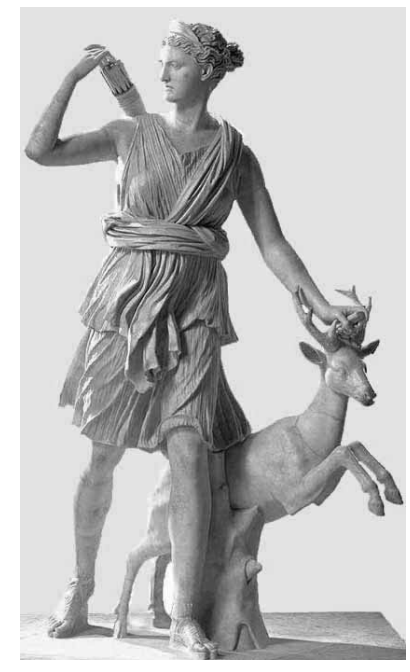

Ártemis de Versalles (Artemis Agrotera). Ubicada en el Museo del Louvre. Copia romana ca. 300 a. C.

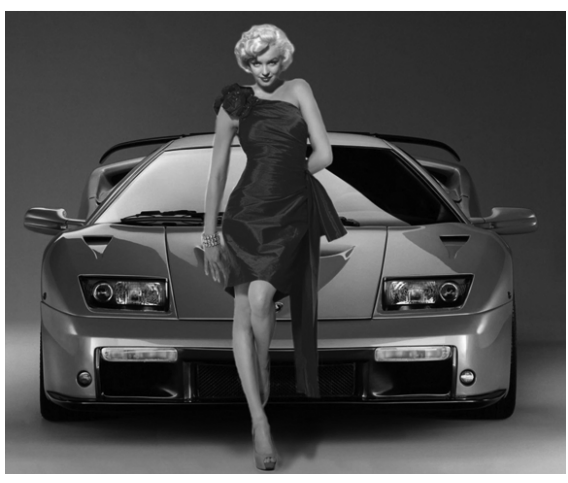

Marilyn Monroe. Imagen publicitaria que fotomonta la imagen de la actriz o de otra mujer personificándola. 
¿Cuál de las dos imágenes parece más hermosa? Esta pregunta suscita inmediatamente otras dos. En primer lugar, ¿cuál de estas dos mujeres es más bella? o, más bien, ¿cuál de las dos imágenes lo es? Consideramos, por supuesto, que una obra de arte puede ser hermosa incluso si el tema representado no lo es. Los griegos, como veremos, también distinguían entre la naturaleza de la cosa representada y la calidad de la representación - uno puede deleitarse, por ejemplo, en la imitación exacta de un sonido o visión que en sí misma es desagradable-, pero no establecían esta distinción en términos de belleza, y esto apunta al núcleo del problema. La segunda pregunta es: ¿en qué sentido estoy yo usando la palabra "bello(a)"? Supongamos, por un momento, que no me estoy refiriendo a la excelencia de la obra de arte respecto a su técnica, sino a la imagen en la obra, por así decirlo. ¿Cuál de las dos mujeres, tal como están representadas en estas obras, es más bella? Aquí en particular, el sentido del término bello parece ser crucial.

¡Que se me permita una pequeña digresión sobre este asunto!, para considerar una diferencia entre las lenguas modernas que, como veremos, resultará ser relevante para nuestro tema. Sucede que el inglés y el español (al menos el español peninsular) difieren de manera importante en el uso de las palabras que significan "bello". En inglés, uno aplica el adjetivo beautiful a las mujeres, no a los hombres, excepto quizá en el caso de los niños. Lo mismo se puede decir de otro adjetivo que pertenece a la misma esfera semántica: pretty. Sería muy extraño referirse a un hombre utilizando este adjetivo, aunque no lo sería en absoluto aplicarlo a una mujer. Así pues, los términos que se refieren a la belleza están profundamente determinados por el género del individuo a quien se apliquen. ${ }^{2}$ En el caso de los hombres, el término apropiado en inglés es handsome, y cuando se usa para calificar a una mujer, sugiere una cierta apariencia o comportamiento masculino - que no es en absoluto necesariamente "feo" o "poco atractivo", pero que es claramente diferente de pretty. En este caso, el inglés se parece al alemán, en el que los adjetivos hübsch y schön se aplican típicamente a las mujeres, pero no a los hombres. Para descartar que esta terminología tan sexista para la belleza sea específica de las lenguas germánicas, bastará con notar que el francés tiene un uso análogo: se habla de una mujer como jolie, pero no típicamente (creo) de

\footnotetext{
${ }^{2}$ Una excepción, quizá, es la palabra escocesa bonnie, que se aplica igualmente a hombres y a mujeres.
} 
un hombre. En turco, güzel se usa para las mujeres, pero no para los hombres (aunque puede aplicarse a cosas como el arte o el tiempo atmosférico, como el inglés beautiful); yaklşikli, sin embargo, se usa sólo para los hombres, en el sentido del inglés handsome. Hay distinciones semejantes, según mis informantes, en sueco, hindi, bengalí, esloveno, húngaro, serbio y muchos otros idiomas. En español, por el contrario, el adjetivo bello(a) se aplica indiferentemente a hombres y mujeres, lo mismo que hermoso(a) o guapo(a). En este sentido, el español es análogo al italiano, donde bello(a) se usa para ambos géneros, y al portugués y también al griego moderno, donde uno puede aplicar el término ó

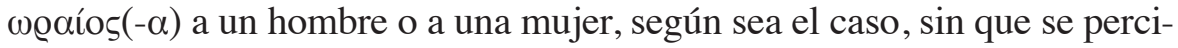
ba ninguna violación del uso ordinario (en el español de América Latina, sin embargo, lindo, en el caso de un hombre, se refiere normalmente a su carácter, no a su apariencia física). Ahora bien, ¿tiene todo esto alguna relevancia? Cuando preguntaba hace un momento cuál de las dos mujeres es más "bella", ¿modificaría nuestra respuesta el hecho de que en una lengua dada el adjetivo esté determinado o no por el género? Yo creo que sí: en particular, si uno preguntara cuál de las dos es la más beautiful, en vez de la más guapa o hermosa, la respuesta podría ser diferente, y si preguntáramos por la más sexy, la respuesta sería, también, otra.

Estas reflexiones plantean una segunda pregunta en relación con las dos imágenes: ¿cuál de las dos les habría parecido más "bella” a los griegos antiguos? No es totalmente inútil imaginar la respuesta de aquellos hombres, pues nos invita a considerar que nuestra noción de belleza podría ser diferente de la suya o, al menos - y esto es un asunto igualmente interesante-, de la noción que nosotros les atribuimos. Pero ¿es posible que estemos idealizando su concepto de belleza, siguiendo los pasos de la noción renacentista de la misma y, por lo tanto, negándonos a aplicar a los antiguos lo que puede parecernos una idea burda de la belleza, como simple "guapura" o incluso - ¡qué horror! - la cualidad de sexy? ¿Es acaso remotamente posible que un griego de la antigüedad considerara a Marilyn Monroe más bella que la diosa Ártemis, que su gusto fuera tan sexualizado como el nuestro (o, al menos, como el de algunos de nosotros)?

Para dar respuesta a esta cuestión debemos investigar la terminología griega sobre la belleza, pero antes de eso, me gustaría plantear otra peculiaridad que presentan los vocablos para belleza, por lo menos en algunas lenguas modernas, incluido el español. Me refiero al término guapo(a), que se usa, como se sabe, comúnmente en España, pero no en todas partes 
de América Latina. Esta palabra es, de nuevo, indiferente al género en su uso, pero tiene el rasgo interesante de que se aplica sólo a los seres humanos: no describimos paisajes, animales o arte como "guapos", sino como "bellos" o "lindos". En este caso, el adjetivo español guapo difiere del inglés beautiful y de los usados en todas las lenguas que he mencionado antes, que no parecen tener un término sujeto a tales restricciones.

Estoy consciente de que aún no he presentado una descripción de la idea actual de belleza, y voy a volver sobre el tema brevemente al final de este texto. Pero ya es hora de concentrarme en la terminología que el griego clásico utilizaba para la belleza, y luego podré determinar en qué medida ésta corresponde al ideal del Renacimiento, que derivaba de la contemplación del arte clásico, o más bien a un sentido más sexualizado de la belleza que nos resulta familiar, pero que es, a la vez, claramente marginal a los valores estéticos modernos.

Cualquiera que aborde la cuestión de la belleza en la Grecia clásica debe inmediatamente enfrentarse a una dificultad fundamental: parece que no hay una palabra que corresponda claramente al término moderno bello. Para ilustrar el problema, cito de un número reciente de la revista Classical Philology, ${ }^{3}$ que es precisamente un volumen especial, dedicado al tema "Beauty, Harmony, and the Good", editado por Elizabeth Asmis. En el primero de los artículos, intitulado "Beauty and the Good: Situating the $\mathrm{Ka}$ lon", el eminente estudioso de la filosofía antigua Aryeh Kosman escribe: "las observaciones de Aristóteles [en muchos de sus textos] nos producen perplejidad sólo en la medida en que traducimos kalon por 'bello' y to kalon por 'belleza' o 'lo bello'”, y prosigue diciendo: "cuando Aristóteles escribe que una persona de coraje aguanta y actúa como lo hace kalou heneka (EN., 1115b23), los traductores lo representan como queriendo decir que tal hombre actúa así, no por causa de lo bello, sino de lo noble". 4 Naturalmente, Kosman tiene tanta razón aquí como en su observación más general de que "existe una historia profunda de incertidumbre sobre cómo traducir propiamente kalon", 5 esta vez en conexión con el diálogo platónico Hipias Maior, que se dedica enteramente a definirlo. "Estos problemas, [afirma Kosman], producen en mí el fuerte deseo (que, naturalmente, voy a reprimir) de decir que los griegos no poseían el concepto de belleza.

\footnotetext{
${ }^{3}$ Classical Philology, 105-4, 2010.

${ }^{4}$ Ib., pp. 344-45.

${ }^{5}$ Ib., p. 346.
} 
Pero lo que sí es correcto es lo siguiente: que el concepto de belleza es lo bastante diferente del de kalon como para que entendamos este deseo del que hablo". Y Kosman prosigue diciendo que hay dos rasgos de la idea moderna de belleza que "no se encuentran en ningún sentido comparable en la noción del kalon: (1) la belleza implica esencialmente el mundo del arte; (2) la belleza implica esencialmente el mundo de la naturaleza". ${ }^{6}$

Como si pretendiera confirmar la ansiedad de Kosman, Rachel Barney comienza su artículo en el volumen (que sigue inmediatamente al de Kosman) de la siguiente manera: "Cuál sea la relación entre lo noble (kalon) y lo bueno (agathon) en el pensamiento de Platón es un rompecabezas": ${ }^{7}$ no hay aquí ningún equívoco sobre la conexión de kalon con la belleza, aunque Barney se pregunta por qué, según Platón, la actitud promovida por el $x \alpha \lambda$ óv "es erôs, no admiración". ${ }^{8}$ Terence Irwin, sin embargo, está dispuesto a ver una ambigüedad o una homonimia en el significado de $\varkappa \alpha \lambda$ óv, por decirlo en sus palabras: "Aristóteles usa kalon tanto para destacar la belleza como la rectitud moral", 9 aunque la ética, en su visión, trata sólo de la rectitud moral, sin sugerir que moralidad y belleza coincidan de alguna forma. Irwin se manifiesta en contra del término bello (o beautiful), y sugiere que noble (fine) o admirable son mejores. ${ }^{10}$ Anton Ford, en su respuesta al artículo de Irwin, cita la siguiente definición que Aristóteles da de $x \alpha \lambda$ óv en su Retórica (1366a33-34): "lo que es a la vez deseable por sí mismo y merecedor de elogio, o lo que complace porque es bueno". ${ }^{11}$

En conjunto, estas discusiones del adjetivo $x \alpha \lambda o ́ v$ en griego clásico no parecen ser de mucha ayuda al decidir cuál de las dos imágenes habría parecido a los griegos más bella, porque no está claro el fundamento en que podríamos basarnos para describir una u otra como "deseable por sí misma" o "que complace porque es buena" - aunque quizá haya quien

${ }^{6} \mathrm{Ib} .$, p. 351.

${ }^{7}$ R. Barney, "Notes on Plato on the Kalon and the Good", Classical Philology, 1054, 2010, pp. 363-377, p. 363.

${ }^{8}$ T. H. Irwin, "The sense and Reference of Kalon in Aristotle", Classical Philology, 105-4, 2010, pp. 381-396, p. 375.

${ }^{9}$ Ib., p. 382.

${ }^{10}$ A. Ford, "Response to Irwin”, Classical Philology, 105-4, 2010, pp. 296-402, p. 396.

${ }^{11}$ Ib., p. 400. 
se incline a suponer que una diosa era "más merecedora de elogio" que una diva del cine - y también porque, incluso si llegáramos a estar de acuerdo en que Ártemis era más $x \alpha \lambda \eta ́$ que Marilyn Monroe en este sentido, es aún dudoso que aquí el significado relevante de la palabra sea "bella" o "beautiful".

Hace poco me pidieron que escribiera un capítulo sobre la belleza para un manual de estética en la antigüedad, y, dadas las dificultades que vengo mencionando, estaba a punto de rechazar el encargo cuando se me ocurrió que podría existir una palabra griega más próxima a nuestro concepto moderno y que pudiera arrojar luz sobre el asunto. El término en

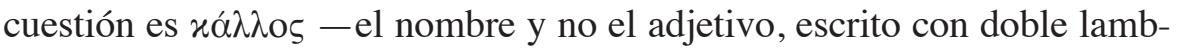
da y con el acento en la primera sílaba en vez de la segunda-, y aunque está obviamente relacionada con el adjetivo $x \alpha \lambda$ ó o $x \alpha \lambda$ óv, mi intuición tenía que ver con la existencia de un abanico de significados bastante más restringido que el del adjetivo. Y, de hecho, una investigación más profunda del término reveló que yo estaba en lo correcto. Lo que también reveló, para mi gran sorpresa, es que nadie, que yo sepa, ha estudiado detalladamente este término, y que todas las discusiones de la belleza en griego antiguo, como las presentadas en los artículos del reciente número de Classical Philology, virtualmente omiten la palabra, o, cuando la citan, la tratan como idéntica a tò $x \alpha \lambda o ́ v$. Esto, creo, es un error, y lo que es más, la semántica del nombre $x \alpha ́ \lambda \lambda o s$ puede, de hecho, ayudarnos a resolver el problema que he planteado en esta charla, es decir, cuál de las dos imágenes le habría parecido más bella a un griego antiguo, al menos en un sentido de "belleza" que era normal en la antigüedad. Además, puede ayudarnos también a ver cómo y por qué el sentido antiguo de belleza se perdió cuando el arte clásico se convirtió en el modelo de la belleza estética en el Renacimiento y en épocas posteriores. Pero antes de afirmar cuál de las dos imágenes era la más bella o, para ponerlo en términos griegos, cuál de las dos poseía xá $\lambda \lambda$ os en mayor grado, debo explicar brevemente los usos de este sustantivo en la literatura griega arcaica y clásica.

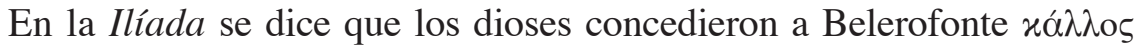

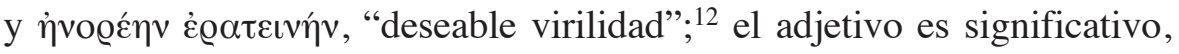
puesto que la mujer de su anfitrión se enamora locamente de él - una reacción a la belleza que es característica, como veremos, y que nos ayuda a definir su papel en los esquemas de pensamiento griegos. Paris

\footnotetext{
${ }^{12}$ Hom., Il., 6, v, 156.
} 
también es bello: Afrodita, tras sacarlo del campo de batalla, le dice a Helena: "Paris está en tu habitación y tu torneado lecho, reluciente en su belleza y vestidos"; ${ }^{13}$ fue su belleza la que inspiró a Helena a escaparse con él, y la escena de su enamoramiento se repite implícitamente en este pasaje de la Ilíada. Aquiles puede describir la consumada belleza de una mujer como rival de la de Afrodita, ${ }^{14}$ que es, por supuesto, el epítome de la belleza. Aristóteles, en la Retórica 1413a32-35, cita este pasaje como un ejemplo de exageración retórica. Un fragmento del historiador Democares ${ }^{15}$ refiere que los atenienses compusieron un himno a Demetrio Poliorcetes, en el que se afirmaba que él era el único dios verdadero, puesto que estaba entre ellos y despierto, proclamando también que había nacido de Poseidón y Afrodita, dado que destacaba en su belleza y su humanidad. Teócrito, quien escribía, claro, en el período helenístico, describe a Afrodita como superior a todas las diosas en belleza (17, v. 45).

Las jóvenes compañeras de Nausicaa poseen una belleza que les han

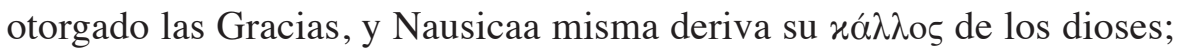
la joven es una novia potencial, y, por tanto, su belleza importa. Así también, se nos cuenta que Neleo se casó con Cloris por su belleza. ${ }^{16}$ En el Himno homérico a Afrodita, ésta se enamora de Anquises, quien recibió su belleza de los dioses, mientras ella misma posee "belleza inmortal”; Zeus, por su parte, raptó a Ganimedes debido a su $x \alpha ́ \lambda \lambda \circ \varsigma .{ }^{17}$

El sentido del término xó $\lambda \lambda$ o comienza, pues, a emerger: se refiere a la belleza física, el tipo de belleza capaz de inspirar pasión o amor. Es en sí mismo una cualidad positiva, siempre que vaya acompañado de virtud. Así, en Eurípides, Andrómaca le dice a su torturadora Hermíone: "no es el kállos, mujer, sino las virtudes, lo que deleita al compañero del lecho"; ${ }^{18}$

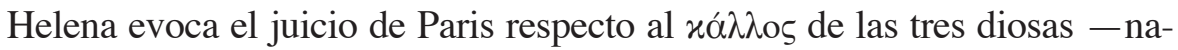
turalmente Afrodita era de antemano la ganadora de este concurso- y lamenta su propia y fatal belleza; ${ }^{19}$ Electra acusa de malvada a una mujer que

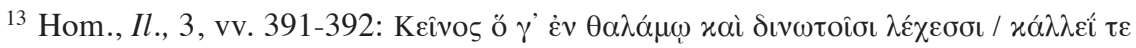

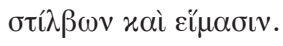

${ }^{14}$ Hom., Il., 9, v. 389.

15 Del libro 21 de sus Historias, citado por Ath., 6, $253 \mathrm{E}$.

${ }^{16}$ Hom., Od., 6, v. 18; 8, v. 457; 11, vv. 281-82.

${ }^{17}$ Hom., Od., 5, vv. 77, 174, 203.

${ }^{18}$ E., Andr., vv. 207-08.

${ }^{19}$ E., Hell., v. 23. 


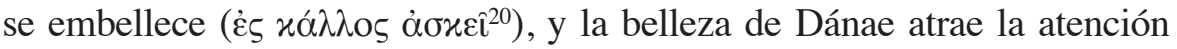
erótica de Zeus. ${ }^{21}$ Jenofonte observa que Alcibíades sufrió la persecución de muchas mujeres por causa de su belleza, ${ }^{22}$ y anota también que se decía de la cortesana Teodota que su belleza era más poderosa que la razón. ${ }^{23}$

El contraste entre el nombre y el adjetivo queda claro en Teócrito,

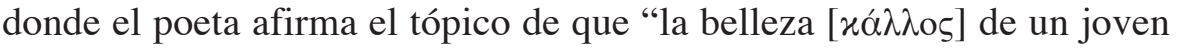
es una cosa buena [ $\varkappa \alpha \lambda o ́ v]$, pero dura poco tiempo". ${ }^{24}$ En el Catálogo homérico de las naves se nos cuenta lo siguiente sobre el oscuro héroe Nireo: "lideró tres naves desde Sime, Nireo, que era el hijo de Aglaea y Carops, el rey, Nireo, el hombre más bello ( $x \alpha$ ć $\lambda \lambda \iota \sigma \tau o \varsigma)$ de entre todos los Dánaos que llegaron a Troya tras el irreprochable hijo de Peleo. Pero era débil, y le seguía un grupo pequeño". ${ }^{25}$ Kó $\lambda \lambda \iota$ เo el superlativo del adjetivo $x \alpha \lambda o ́ \varsigma$, pero aquí evidentemente indica la belleza física de Nireo más que su nobleza de nacimiento o carácter. En todo caso, ésta es la forma en que lo entendían los griegos mismos, pues el Etymologicum magnum, evidentemente con base en los escolios más antiguos, dice:

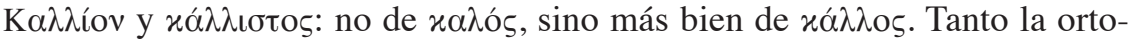
grafía como el sentido confirman esto, puesto que $x \alpha \lambda$ ó $s$ se escribe con una lambda, xá $\lambda \lambda$ os con dos; también el sentido, puesto que el poeta [i. e., Homero] aplica normalmente $x \alpha \lambda o ́ s$ a la hombría, igual que, por el contrario, aplica xaxóv a la debilidad -pero sabe que Nireo es débil, y, sin embargo,

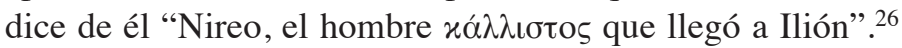

El argumento de que el comparativo y superlativo derivan del nom-

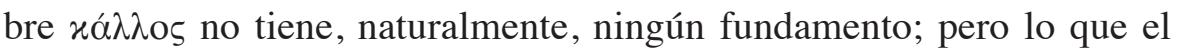

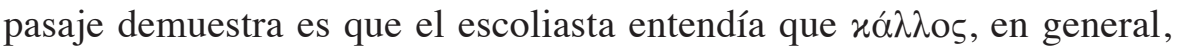
indicaba belleza física, y aunque el adjetivo $x \alpha \lambda$ ó $\varsigma$ pudiera referirse a la belleza, tenía un abanico de significados mucho más amplio y, cuando

\footnotetext{
${ }^{20}$ E., El., v. 1073.

${ }^{21}$ E. fr. 1132.

${ }^{22}$ En sus Mem., 1, 2, 24.

${ }^{23} \mathrm{X} .$, Mem., 3, 11, 1 .

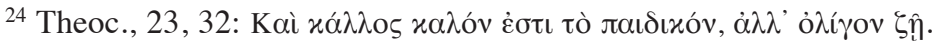

${ }^{25}$ Hom., Il., 2, vv. 671-675.

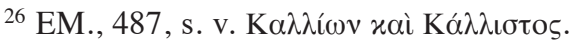


éste se usaba para hombres adultos, la mayor parte de las veces llevaba la connotación de excelencia moral.

Doy aquí unos cuantos ejemplos más de la palabra xá $\lambda \lambda$ os, extraídos de

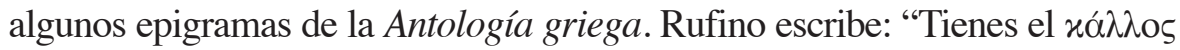
de Cipris [i. e., Afrodita], la boca de Persuasión, el cuerpo y juventud de las Estaciones Primaverales, la voz de Calíope, la mente y modestia de Temis, los brazos de Atenea; las Gracias son cuatro contigo, File". ${ }^{27}$ Ká $\lambda \lambda$ os no aparece como principal atributo de Atenea o de la Musa; es específico

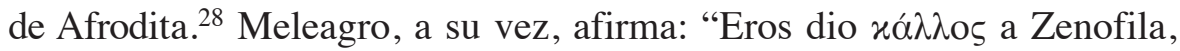
Cipris le dio sus pociones eróticas para poseer, y las gracias le dieron su gracia"; ${ }^{29}$ la relación entre belleza y amor erótico es clara. Asclepíades escribe que se deshace como la cera junto al fuego cuando ve la belleza de Dídima. ${ }^{30}$ Y Meleagro, una vez más, dice que "Su dulce belleza relumbra como un relámpago; ¿lo ves? Echa llamas por sus ojos. ¿Ha proclamado Eros a un joven 'guerrero del relámpago'?" 31

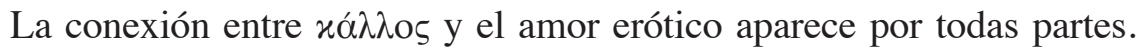
Si queremos un ejemplo de una mujer con la belleza de Afrodita, lo más sencillo sería mirar simplemente una imagen de esta diosa; he elegido la famosa estatua de Praxíteles esculpida en el siglo IV a. C. y situada en el templo de la diosa en Cnido.

Ahora, tomando esta imagen como nuestro modelo de mujer, o diosa,

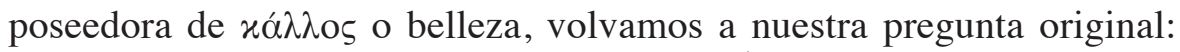
un griego antiguo ¿a qué imagen, a la de Ártemis o a la de Marilyn Monroe, le habría atribuido el don de la belleza? Me inclino a pensar que Marilyn habría ganado la competencia, como lo hizo Afrodita cuando puso en marcha la guerra de Troya.

Querría aclarar un punto antes de pasar a la segunda cuestión planteada, ¿por qué este sentido de xá $\lambda \lambda$ o 5 no parece haberse conservado en las concepciones modernas de belleza clásica? Primero, no pretendo sugerir que los griegos antiguos tuvieran necesariamente los mismos estándares de belleza femenina o efébica que tenemos hoy. En nuestros días, la

${ }^{27} A P ., 5,70$.

${ }^{28}$ Cf. $A P ., 5,73,5-6 ; 5,92,1 ; 5,140$ de Meleagro.

${ }^{29} A P ., 5,196$.

${ }^{30} A P ., 5,120$.

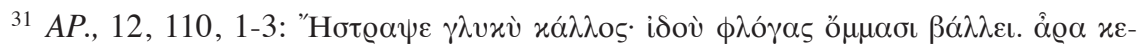

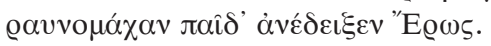




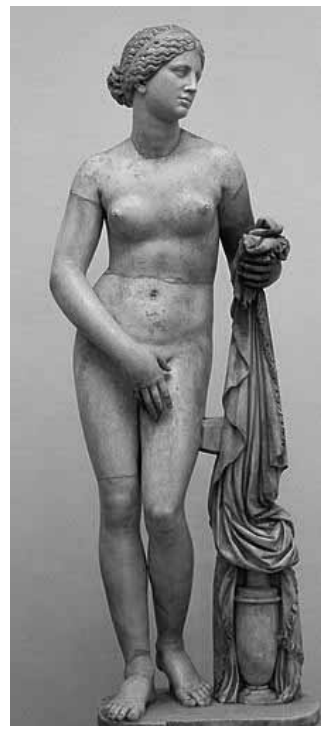

Afrodita Cnidia de Praxíteles (350-340 a. C.), ubicada en Museo del Palacio Altemps, Roma. Copia romana del s. I a. C., llamada de "Altemps" o "Ludovisi".

visión del amor pederástico es muy diferente, y los ideales de belleza femenina han ido cambiando notoriamente: hubo épocas que prefirieron las figuras más robustas y, otras, las figuras más delgadas, hasta llegar a las anoréxicas. Lo que quiero decir es que los griegos antiguos asociaban la belleza humana con el deseo erótico, y lo mismo hacemos nosotros en ciertos contextos, a pesar de que también usamos los términos belleza y bello o hermoso más ampliamente, como cuando decimos que es un lugar bello, o un día hermoso (los griegos podían adscribir xó $\lambda \lambda$ o a estas mismas cosas, como veremos en un momento). Segundo, está claro que el adjetivo $x \alpha \lambda o ́ \varsigma$ o (en el neutro) $x \alpha \lambda$ óv podía referirse perfectamente a la belleza en el sentido de $x \alpha ́ \lambda \lambda$ os. Terence Irwin tiene razón cuando señala que $x \alpha \lambda o ́ s$ tiene más de un sentido, y que uno de esos significados es "bello." Lo que espero haber demostrado es que

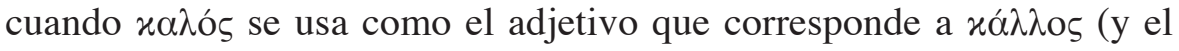
adjetivo es mucho más común en griego clásico que el nombre), sugiere típicamente un atractivo erótico, aunque puede también referirse a la belleza en contextos no amatorios.

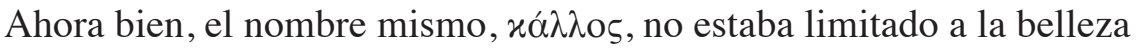
humana, sino que, ya desde Homero, podía, por ejemplo, referirse a una 
copa. ${ }^{32}$ Pero ¿qué significaba en tales casos? Creo que se puede empezar a elaborar una respuesta si se considera que los griegos reflexionaron sobre por qué ciertas formas humanas parecían hermosas o atractivas, y examinaron el asunto especialmente en conexión con las obras de arte. La desnudez, por sí sola, al fin y al cabo, no era el problema; ¿qué cosa podía hacer bellos a una Afrodita o a un hombre desnudos, pongamos por caso? El Canon de Policleto, un tratado compuesto hacia fines del siglo $\mathrm{v}$ a. C., puso en marcha una serie de principios artísticos ilustrados en la famosa estatua del Doríforo o Lancero. Según Galeno, el filósofo estoico Crisipo sostenía que:

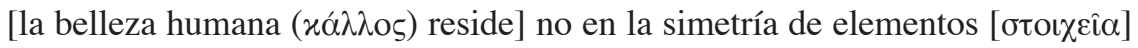
sino en la de las partes [o porciones, $\mu$ ó ıı $\alpha$, esto es, de dedo con dedo, y de estos colectivamente con la mano y la muñeca, y de todos ellos con el antebrazo y el brazo, y de todos estos con todo lo demás, como se describe en el Canon de Policleto. Pues, tras enseñarnos en ese tratado todas las simetrías del cuerpo, Policleto confirmó su argumento con una obra: hizo una estatua de acuerdo con los principios de su argumento, y llamó a la estatua misma, como al tratado, el Canon. Que la belleza del cuerpo reside en la simetría de sus partes, está de acuerdo con los puntos de vista de todos los médicos y filósofos. ${ }^{33}$

El tratado de Policleto tuvo una enorme influencia, y sin duda formaba parte de la base que permitía la transferencia de la idea de belleza a partir de los objetos físicos, y, sobre todo, de la forma humana, hasta llegar a las cosas menos tangibles en las que se puede discernir una armonía de elementos. ${ }^{34}$

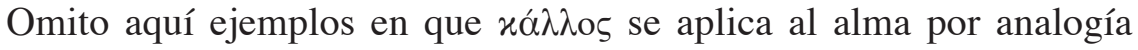
con el cuerpo, como en Platón y los neoplatónicos, dado que se trata de un uso especializado y a menudo metafórico. Pero merece la pena

${ }^{32}$ Hom., Il., 7, vv. 40-42.

${ }^{33}$ Claudii Galeni, De placitis Hippocratis et Platonis libri novem, V, 448 (vol I, recensuit et explanavit I, Müller, Lipsiae, B. G. Teubneri, 1874), p. 425.

34 Sobre el Canon de Policleto, véase la tesis de Alicia Montemayor García, La trama de los discursos y las artes: El Canon de Policleto de Argos (UNAM, 2008), con una lista de todas las fuentes textuales pertenecientes al Canon. Sobre la simetría como medida de la belleza, puede consultarse Andrew Barker, "Mathematical Beauty Made Audible: Musical Ethics in Ptolemy's Harmonics", en el número de Classical Philology citado arriba, p. 407, y especialmente Pl., Ti., 87c-e y Phil., 64d-65a. 
notar que el término se aplicaba también al estilo literario. Aristóteles, por ejemplo, en su Retórica (1405b5-8), dice que la belleza ( $x \alpha ́ \lambda \lambda \mathrm{o} \varsigma$ ) de una palabra (óvo $\mu \alpha$ ) se encuentra en los sonidos o en el sentido ( $\dot{\varepsilon} v$

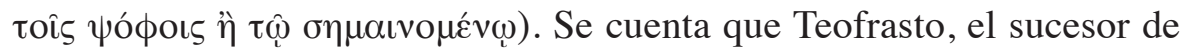
Aristóteles, en un fragmento (95, 1 Wimmer) que probablemente proce-

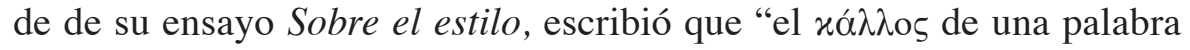
[óvó $\mu \alpha \tau o \varsigma$ ] es lo que resulta placentero al oído o a la vista o es noble en su significado". Pero cuando llegamos a discusiones más extensas del término, la importancia de la simetría queda patente. Así, Hermógenes, en su tratado Sobre el estilo (s. II d. C.), afirma:

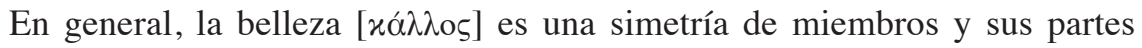

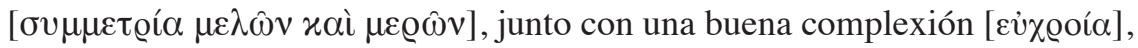
y gracias a ellas un discurso $\left[\lambda\right.$ ó$\left._{\gamma} \mathrm{s}\right]$ se hace bello.... Es, pues, necesario, si

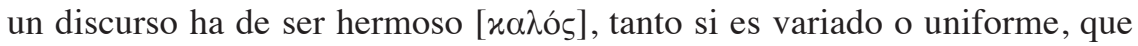

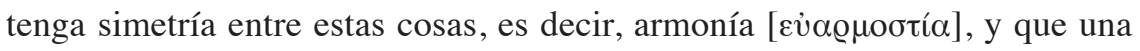
especie de buen tono florezca en él, adoptando la forma de una sola cualidad del carácter en toda la extensión del discurso, y que algunos, con toda la razón, llaman naturalmente su color $[\chi \varrho \omega \hat{\mu \alpha}]$.

Había entonces buenas razones para que los artistas y estudiosos del Renacimiento, que intentaron establecer cánones ideales de belleza, dado que se inspiraban en los textos y obras de arte griegos y romanos recientemente descubiertos con nuevo aprecio, pensaran que la simetría y la armonía eran sus elementos esenciales. Así, a mediados del siglo XVI, en sus Vidas de los más eminentes arquitectos, pintores y escultores italianos, Giorgio Vasari, que tomaba su inspiración en las teorías neoplatónicas de espiritualidad y estética tal como las había diseminado Ficino, situaba la belleza primordialmente en ideas de armonía y proporción (su ideal de tal belleza era el David de Miguel Ángel). Como escribió Vasari: "La belleza nace del orden y la proporción". ${ }^{35}$ Sin duda, la blancura prístina de las marmóreas esculturas antiguas - cuyo brillo y, aún más, sus fuertes colores se han deslucido por el paso del tiempo- contribuyó al sentimiento de que el arte antiguo era de alguna manera forma pura, fría, matemática y elevada. No es este el lugar para trazar la subsiguiente historia de este concepto de belleza, que aún hoy sigue siendo dominante (o aparece por todas partes).

${ }^{35}$ Citado en Liana de Girolami Cheney, Giorgio Vasari's Teachers: Sacred and Profane Art (New York, Peter Lang, 2007), p. 117. 
Pero es importante notar que, fuera de los tratados técnicos sobre el arte o el estilo y la teorización metafísica de los platónicos, el significado an-

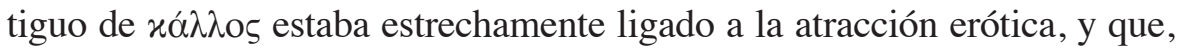
al despreciar este sentido del término, la recepción moderna de los ideales estéticos clásicos constituyó, de forma importante, una distorsión de la manera en que los griegos pensaban en la belleza. Me temo que, después de todo, los que han considerado que Marilyn Monroe es más bella que Ártemis puede que tengan a los antiguos griegos de su parte. 